\title{
PARA ALÉM dos OBSTÁCUlos: EXPERIÊNCIAS DE CONSULTAS PÚBLICAS E A POSSIBILIDADE DE ÉTICA E RELEVÂNCIA NA PARTICIPAÇÃo
}

\author{
Maria Fernandes-Jesus \\ Centro de Investigação e Intervenção Social, Instituto Universitário de Lisboa (ISCTE-IUL), Portugal
}

Eunice Castro Seixas

Centro de Investigação em Sociologia Económica e das Organizações (SOCIUS), Universidade de Lisboa, Portugal

\author{
Anabela Carvalho
}

Centro de Estudos de Comunicação e Sociedade, Instituto de Ciências Sociais, Universidade do Minho, Portugal

\begin{abstract}
Resumo
O procedimento de consulta pública tem sido, cada vez mais, utilizado em projetos com impacto ambiental, supostamente como uma forma de assegurar que as preocupações e sugestões das pessoas e das comunidades interessadas e afetadas pelos projetos são tidas em conta. No entanto, esta forma de participação pública tem vindo a ser bastante criticada, por ser uma prática meramente simbólica e sem consequências concretas. Neste artigo, apresentamos um estudo focado no processo de consulta pública relativo ao projeto de construção de uma linha de muita alta tensão entre o Norte de Portugal e a Galiza (Espanha). Especificamente, analisamos discursos de cidadãos relativamente às barreiras à sua participação pública, bem como diversas recomendações para desenvolvimento de processos de consulta pública éticos e relevantes. A análise apresentada é baseada em entrevistas semiestruturadas a 26 pessoas e em cinco grupos focais $(\mathrm{N}=37)$ realizados em quatro localidades do Norte de Portugal. A partir dos discursos sobre as diversas experiências de participação, discutimos significados de ética e relevância nas questões de acesso, legitimidade e influência em processos de consulta pública.
\end{abstract}

\section{BEYOND THE HINDRANCES: EXPERIENCES OF PUBLIC CONSULTATIONS AND THE POSSIBILITY OF ETHICS AND RELEVANCE IN PARTICIPATION}

\begin{abstract}
Public consultations are increasingly used in projects with environmental impact, allegedly as a way to ensure that affected people and communities have their concerns recognised and addressed. There have been multiple criticisms of this form of public participation, with consultations frequently viewed as a tokenistic practice. In this study, we focus on a public consultation on extra-high voltage power lines projected to go from northern Portugal to northwestern Spain. We analyse citizens' discourses regarding hindrances to participation as well as envisaged possibilities to improve it. The study draws on semi-structured interviews with 26 people and five focus groups discussions $(\mathrm{N}=37)$ carried out in localities in the north of Portugal that would be affected
\end{abstract}


by the project. Based on citizens' narrated experiences of participation we discuss the relevance and the ethics of participation in access, standing and influence in public consultations processes.

KEYWORDS

consultation; discourses; ethics; public participation; relevance

\section{INTRODUÇÃO}

Com vista a envolver os cidadãos nos processos de tomada de decisão, a participação pública tornou-se, essencialmente nas últimas décadas, um mecanismo bastante utilizado na elaboração de políticas públicas. Por participação pública entende-se um espaço aberto à participação do público, iniciado pelas instituições (top-down) (Cornwall, 2002). A participação pública pode ser definida como um processo de envolvimento do público na formulação, adoção e implementação das agendas governamentais e/ou corporativas (Fishkin, 2009; Rowe \& Frewer, 2004). Normalmente, implica uma ou mais formas de interação entre o governo (ou outra instituição política responsável) e o público (O'Faircheallaigh, 2010), e pressupõe que as sugestões do público serão tidas em conta na elaboração de políticas públicas (Rowe \& Frewer, 2000, 2004). Importa salientar que, tal como outras formas de participação (e.g., Carpentier, 2012; Ekman \& Amnã, 2012), a participação pública é um fenómeno complexo e o próprio termo é bastante contestado (Rowe \& Frewer, 2004). Uma definição compreensiva de participação pública deve reconhecer os seus vários níveis e formatos. Neste sentido, várias propostas têm procurado analisar a participação pública como um processo contínuo, em que os níveis mais elevados de participação corresponderiam ao controlo - pelos cidadãos - de todo o processo e dos resultados da participação (Arnstein, 1969)'. Dentro das diversas formas de participação pública, a consulta pública tem sido um dos procedimentos mais utilizados (Kaehne \& Taylor, 2016; Senecah, 2004). Contudo, apesar da inúmera literatura existente, são poucas as evidências de que as consultas públicas permitam aos cidadãos influenciarem os processos de tomada de decisão (Kaehne \& Taylor, 2016; van Damme \& Brans, 2012). Pelo contrário, vários estudos sugerem que a consulta pública é um procedimento excessivamente top-down, colocado à disposição da população meramente como uma formalidade (e.g., Hendry, 2004; Martin, 2007).

Neste sentido, torna-se fundamental responder à seguinte questão: "o que são processos de participação de qualidade?". Vários estudos têm procurado definir e caraterizar os ingredientes responsáveis por processos de participação pública bem-sucedidos (e.g., Rowe \& Frewer, 2000, 2004; Rowe, Horlick-jones, Walls, Poortinga \& Pidgeon, 2008; Webler \& Tuller, 2006). No entanto, a maioria dos estudos desconsidera as vozes e as experiências dos cidadãos que participam nos processos de consulta pública. Torna-se assim fundamental compreender o modo como as pessoas avaliam os processos de participação, e também compreender quais as expectativas dos cidadãos relativamente

\footnotetext{
' Informação também retirada de https://www.iap2.org/page/about
} 
à participação pública (Webler \& Tuler, 2006), de forma a potenciar o desenvolvimento de processos de participação pública éticos e relevantes (Fox \& Murphy, 2012) ${ }^{2}$. Neste artigo, discutimos possibilidades de desenvolver processos de consulta pública éticos e relevantes, a partir de recomendações para a adoção de um código de ética nos processos de participação pública (Fox \& Murphy, 2012) e inspiradas por abordagens críticas sobre a "ética do cuidado" (e.g., Scourfield \& Burch, 2010; Tronto, 2010).

Especificamente, examinamos um processo de consulta pública, decorrido em 2013, sobre o projeto de construção de uma Linha de Muito Alta Tensão (LMAT) entre Barcelos (Norte de Portugal) e Fontefria (Espanha). O projeto previa que a linha permitisse transportar $400 \mathrm{kv}$, que é o valor máximo que normalmente pode ser projetado (ainda assim, bastante incomum). Para além disso, as torres previstas eram excecionalmente altas, até 75 metros, e as faixas de segurança de 100 metros de largura, estendendo-se por várias centenas de quilómetros em Portugal. A rota atravessaria uma área territorial bastante diversificada, incluindo partes de floresta, terrenos de agricultura de pequena-escala e vários tipos de localidades habitadas. A rota projetada não incluiria cidades, mas um número significativo de aldeias e outras áreas residenciais seriam diretamente afetadas. De acordo com a lei portuguesa (Decreto-Lei n. ${ }^{\circ} 69 / 2000$ e mudanças introduzidas com o Decreto-Lei n. ${ }^{\circ}$ 197/2005), é obrigatória a realização de uma Avaliação do Impacto Ambiental (AIA) dos projetos que visam a construção de linhas aéreas de transporte de eletricidade com uma voltagem igual ou superior a $220 \mathrm{kv}$, cujo cumprimento seja superior a $15 \mathrm{~km}$ e que tenham subestações com linhas acima de $110 \mathrm{kv}$ (Decreto-Lei n. ${ }^{\circ} 69 / 2000$, Anexo 1, 19). O procedimento da consulta pública "visa a recolha de opiniões, sugestões e outros contributos dos interessados sobre cada projeto sujeito a AIA" (Decreto-Lei 197/2005, artigo 2, alínea f). Neste contexto, o "público interessado" refere-se aos "titulares de direitos subjetivos ou de interesses legalmente protegidos, no âmbito das decisões tomadas no procedimento administrativo de AIA, bem como o público afetado ou suscetível de ser afetado por essa decisão, designadamente as organizações não governamentais de ambiente (ONGA)" (Decreto-Lei n. ${ }^{\circ}$ 197/2005, artigo 2, alínea r).

Relativamente ao projeto de construção da LMAT no Norte de Portugal, o Estado português determinou que a consulta pública estivesse aberta por um período de 30 a 50 dias e que o formato de consulta fosse a submissão de comentários escritos. Parte do projeto poderia ser consultado nos edifícios das juntas de freguesia e das câmaras municipais interessadas. No total, foram submetidas 178 contribuições por parte dos municípios, das juntas de freguesia, de associações locais, empresas, partidos políticos e cidadãos (Lusa, 2015). Simultaneamente, várias comunidades locais contestaram o projeto, (por vezes, através da organização e mobilização coordenada entre os dois países afetados) através de diversas manifestações e protestos, e do boicote às eleições europeias de 2015. Contudo, é ainda pouco claro que impacto estas e outras mobilizações tiveram na decisão de suspender o projeto por parte das entidades competentes. De facto, atualmente o projeto encontra-se suspenso, e a decisão final não foi formalmente publicada.

\footnotetext{
${ }^{2}$ Informação também retirada de https://www.iap2.org/page/about

3 Informação também retirada de https://www.iap2.org/page/about
} 
Neste artigo, a análise apresentada foca-se essencialmente nos discursos dos cidadãos relativamente a questões relacionadas com o seu acesso, legitimidade ${ }^{4}$ e influência (Senecah, 2004) na consulta pública. Procurámos responder às seguintes questões: que obstáculos existem nos processos de consulta? O que é um processo de consulta pública ético e relevante? O que é isso significa para as pessoas? Que papel poderão as consultas públicas ter na revitalização da participação? Em última instância, este estudo procura ir além do foco no que está "errado" ou é "negativo" no procedimento de consulta pública, e visa contribuir para a construção de abordagens que permitam resgatar a participação, mesmo em formatos formais e tradicionais. Ao abordamos estas questões a partir das experiências narradas pelas pessoas que foram convidadas (mesmo que não nominalmente) a participar no processo de consulta pública, refletimos sobre dimensões mais gerais relacionadas com a relevância e a ética de processos de participação pública.

\section{ÉTICA E RELEVÂNCIA NA PARTICIPAÇÃo PÚBLICA}

A literatura na área da participação tem vindo a ser marcada por duas linhas de investigação distintas. Enquanto diversos autores enfatizam um declínio acentuado nos níveis de participação formal (e.g., Amnå \& Ekman, 2014; Dassonneville \& Hooghe, 2018; Putnam, 2000), outros focam-se na análise de formas não convencionais de participação na esfera política (e.g., Dalton, 2008, 2015; Norris, 2002, 2011). A ideia de que a participação é um princípio vital de qualquer sociedade democrática e que implica necessariamente o envolvimento ativo dos cidadãos nos processos de tomada de decisão política tem sido transversal ao debate sobre o declínio ou a emergência de formas de participação (Fishkin, 2009). Deste modo, os processos de participação devem providenciar as ferramentas necessárias para que todos os cidadãos possam ter as mesmas oportunidades de influenciar as decisões governamentais, assegurando assim a condição fundamental de igualdade política (Verba, 2003), que permite a manutenção do sistema democrático e é um garante da respetiva qualidade (Verba, 2003; Verba, Schlozman \& Brady, 1995). Não obstante a tendência para considerar a participação pública como algo intrinsecamente "bom", que apresenta vários benefícios para a democracia (e.g., Stewart \& Sinclair, 2007), o modo como os processos de participação pública são desenhados e implementados continua a ser bastante controverso (e.g., Arnstein, 1969; Hendry, 2004; O'Faircheallaigh, 2010). Neste aspeto, vários autores têm vindo a questionar a "utilidade", "eficácia" e "produtividade" dos processos de participação pública, nomeadamente na capacidade de melhorar os processos de tomada de decisão e/ou as relações comunitárias (Rowe et al., 2008; Rowe \& Frewer, 2000, 2004; Senecah, 2004). Neste sentido, tem sido sugerido que os processos de participação pública sejam avaliados através de um conjunto de critérios pré-definidos, nomeadamente relacionados com o reconhecimento do processo e com o próprio processo de participação. Os critérios

\footnotetext{
4 "Standing" foi o termo originalmente proposto por Senecah (2004). Tivemos dificuldade em encontrar um termo equivalente na língua portuguesa. Optámos pelo termo "legitimidade", que nos pareceu ser adequado para representar a posição/lugar/estatuto reconhecido aos cidadãos nos processos de participação pública, e que vai de encontro à definição proposta de "standing".
} 
relacionados com o reconhecimento referem-se essencialmente a dimensões associadas com o nível de representatividade, independência, influência e transparência. Por sua vez, os critérios associados com o processo de participação, prendem-se essencialmente com o modo como a tarefa é definida, o nível de acessibilidade dos recursos e o tipo de estrutura utilizada na tomada de decisão, bem como a relação entre custos e benefícios associados ao processo (Rowe et al., 2008; Rowe \& Frewer, 2000, 2004).

Ao considerarem que estes critérios são universais, estas perspetivas negligenciam a importância das experiências subjetivas de participação e o papel de variáveis contextuais. Neste sentido, Webler e Tuler (2006) defendem que a definição de um processo de participação realmente significativo não é necessariamente algo consensual. Por sua vez, Baker e Chapin (2018) argumentam que os principais pontos de discordância estão relacionados com a influência que variáveis contextuais podem ter, nomeadamente dimensões relacionadas com a distribuição de poder, liderança, confiança, transparência e abertura política.

Apesar de ser possível identificar uma mudança no sentido de uma abordagem compreensiva e contextual dos processos de participação pública, a maior parte da investigação realizada continua ainda a privilegiar critérios bastante instrumentais. De facto, poucos estudos têm procurado examinar os processos de participação pública na perspetiva dos cidadãos leigos. Senecah (2004), na sua "teoria prática" chamada "Trindade da Voz", analisou estes processos focando-se em dimensões relacionadas com o acesso, a legitimidade, e a influência. Com base nesta proposta, as questões de acesso, legitimidade processual e influência devem ser guiadas por uma relação contínua de construção de confiança, de modo a potenciar o desenvolvimento da comunidade e a promover a coesão comunitária (Senecah, 2004). Senecah (2004) propõe assim uma análise do modo como as pessoas falam sobre as suas experiências de participação, nomeadamente sobre as oportunidades de expressar as suas escolhas e opiniões (acesso); a legitimidade cívica do processo de participação, incluindo o respeito, estima e consideração que as opiniões das pessoas recebem (legitimidade); e o impacto que estas vozes têm no processo de tomada de decisão (influência). Consideramos que a abordagem proposta por Senecah (2004) representa uma inflexão na forma como a participação pública é tendencialmente analisada, uma vez que procura incentivar análises focadas no processo de participação e não no produto/resultado da participação (Davies, 2001). Neste sentido, a teoria referida providencia uma estrutura relevante que permite olhar para a ética das consultas públicas.

Vários autores têm vindo a sugerir a necessidade de desenvolver um código de ética para utilizar nos processos de participação pública, de modo a assegurar que os processos têm um propósito e capacidade de influência (Baker \& Chapin, 2018; Davies, 2001; Fox \& Murphy, 2012; Senecah, 2004). Por exemplo, a Associação Internacional de Participação Pública ${ }^{5}$, desenvolveu uma lista de orientações que sugere a necessidade de assegurar os seguintes princípios: propósito, confiança e credibilidade do processo, transparência e abertura ao público, acesso ao processo e respeito pelas comunidades. No entanto, apesar

${ }_{5}$ Informação retirada de https://www.iap2.org/page/about 
das várias propostas, os códigos de ética desenvolvidos até então consistem meramente numa lista de aspirações que devem guiar a intervenção dos especialistas (Conrad, Cassar, Christie \& Fazey, 2011) ${ }^{6}$, e cuja implementação depende dos atores com mais poder (que normalmente são as entidades governamentais ou empresas) (Fox \& Murphy, 2012).

Salvaguardar a ética nos processos de consulta pública implica desafiar relações de poder pré-existentes (Cornwall, 2002), de modo a assegurar que as preocupações das pessoas (com menos poder) são reconhecidas e consideradas como legítimas através de processos democráticos de tomada de decisão (O'Faircheallaigh, 2010). Cabe à entidade que lidera o processo de consulta garantir que não existe qualquer violação dos princípios éticos, o que passa por não permitir mentiras, quebra de promessas; manipulação; convidar o público a participar apenas em algumas fases; potenciar participação apenas como uma formalidade, etc. (Fox \& Murphy, 2012). De forma sucinta, implica necessariamente considerar as necessidades, contribuições e perspetivas dos diferentes atores envolvidos no processo. Segundo Senecah (2004), implica providenciar oportunidades de acesso, legitimidade e influência. Envolve também olhar para as consultas públicas como espaços de (des)politização onde diferentes subjetividades políticas podem (ou não) emergir, ser ouvidas e/ou tidas em consideração (Krause \& Schramm, 2011). Num contexto de participação pública politizada, os cidadãos teriam oportunidades de exercer agência política (Carvalho, Wessel \& Maeseele, 2016) e de debater diferentes possibilidades e alternativas (Pepermans \& Maeseele, 2016).

Inspiradas pelos vários estudos e propostas teóricas referidas anteriormente (e.g., Fox \& Murphy, 2012; Krause \& Schramm, 2011; Senecah, 2004; Tronto, 2010)7, propomos, neste artigo, que os processos de participação pública possam ser considerados éticos quando se reúnem as seguintes condições: as questões de acesso, legitimidade e influência (Senecah, 2004) são percecionadas como transparentes e de confiança pelos vários atores envolvidos; o público interessado tem oportunidade de participação, e os recursos e ferramentas de participação são acessíveis; as visões e opiniões do público são valorizadas no processo de tomada de decisão; o poder é igualmente partilhado, e a comunidade local tem poder para influenciar todas as fases do processo; e finalmente, todas as pessoas interessadas no processo têm acesso igual e justo ao processo de participação pública.

Neste artigo, analisamos estes aspetos através de uma abordagem discursiva, que procura dar centralidade às dimensões éticas nas questões de acesso, legitimidade e influência (Senecah, 2004). Fazemo-lo através da análise das experiências narradas pelos cidadãos, o que constitui uma abordagem inovadora na forma como se analisam os processos de participação pública. De facto, apesar de vários estudos terem vindo a sugerir a necessidade de estabelecer princípios éticos para a participação pública (Fox \& Murphy, 2012; Rowe \& Frewer, 2004) ${ }^{8}$, poucos estudos analisaram os processos de consulta pública através de uma abordagem discursiva, especialmente dando ênfase às dimensões éticas ou a partir da perspetiva dos cidadãos.

\footnotetext{
${ }^{6}$ Informação também retirada de https://www.iap2.org/page/about

7 Informação também retirada de https://www.iap2.org/page/about

${ }^{8}$ Informação também retirada de https://www.iap2.org/page/about
} 


\section{DESENHO METODOLÓGICO E PROCEDIMENTOS}

Este estudo assume uma abordagem metodológica qualitativa, através da combinação de entrevistas e grupos focais. No total, analisamos 15 entrevistas individuais, cinco entrevistas em grupos e cinco grupos focais. Os dados foram recolhidos entre março e maio de 2014. A combinação de entrevistas e de grupos focais permitiu a análise de uma variedade de discursos sobre experiências de participação pública, bem como das possibilidades de ação política em processos de consulta pública (Häkli \& Kallio, 2014).

\section{ENTREVISTAS}

As entrevistas foram conduzidas nas quatro localidades abrangidas pelo projeto de construção da LMAL: Barcelinhos (concelho de Barcelos), Gemieira (Ponte de Lima), Ribeira (Ponte de Lima), e Monção (Monção). No total, foram entrevistadas 26 pessoas, com uma duração média de cerca de 16 minutos por entrevista.

Quinze pessoas foram entrevistadas individualmente e cinco entrevistas foram conduzidas em pequenos grupos (duas a três pessoas por grupo; um participante foi entrevistado em ambos os formatos). Utilizou-se uma amostra de conveniência (Etikan, Musa \& Alkassim, 2016), sendo que a maior parte das entrevistas foram conduzidas em espaços públicos, nomeadamente cafés, jardins e praças (outras decorreram noutro tipo de espaços públicos como: uma loja, um hotel e uma junta de freguesia). Tendo em conta que esses espaços públicos (e.g., cafés, praças) continuam a ser importantes pontos de encontro nas vilas e aldeias, os habitantes foram abordados e convidados a participar no estudo nesses contextos "naturais". A amostra é constituída por habitantes que quando abordados nesses "contextos naturais", aceitaram participar no estudo (Etikan et al., 2016). Deste modo, foi possível aceder às dinâmicas de sociabilidade dessas localidades, ainda que de forma limitada. Como encontramos pessoas a frequentar os espaços referidos, ora individualmente ora em pequenos grupos, decidimos conduzir entrevistas em ambos os formatos. A combinação de entrevistas individuais e em grupos naturais permitiu recolher discursos produzidos em vários formatos de interação.

Em termos de caraterização sociodemográfica, a amostra é maioritariamente constituída por homens ( 18 homens, sete mulheres), com uma média de idade de 54 anos. A distribuição da amostra em termos de idade e género reflete, muito provavelmente, $\mathrm{O}$ tipo de população que passa tempo em espaços públicos durante o horário laboral. Apesar de algum enviesamento devido ao facto de termos conduzido as entrevistas durante o horário de trabalho, a média de idade dos entrevistados reflete também as características demográficas de várias vilas e aldeias portuguesas, que nos últimos anos sofreram muito com o êxodo rural.

As primeiras questões colocadas tinham o objetivo de quebrar o gelo, e simultaneamente compreender a ligação dos entrevistados à comunidade local: "é de Barcelinhos? Há quanto tempo vive aqui? Gosta de viver aqui?". De seguida, exploramos as experiências e perceções sobre participação cívica/política, nomeadamente através de questões relacionadas com a comunidade local dos participantes, e com os motivos para a (não) participação. Num momento posterior, as questões focaram-se no sentimento de influência política (e.g., As pessoas podem contribuir para a alteração de 
políticas? De que forma?). De seguida, procurámos compreender se os participantes tinham conhecimento do projeto de construção da LMAT e abordámos as experiências de participação no procedimento de consulta pública (e.g., Já ouviu falar da LMAT? E do processo de consulta pública, ouviu falar? Participou?). Por fim, foram colocadas algumas questões relacionadas com a responsabilidade na tomada de decisão em projetos ambientais (e.g., Quem é que tem responsabilidade para decidir sobre questões como a instalação da linha? Quem é que acha que deveria ter essa responsabilidade?).

\section{GRUPOS FOCAIS}

De forma complementar às entrevistas, foram conduzidos vários grupos focais. Essencialmente, o objetivo era aceder aos processos de influência e interação social, confirmados pelas nossas entrevistas de grupo como dimensões importantes e relevantes para a investigação. Ao permitirem recriar algumas dinâmicas sociais de grupos naturais, os grupos focais permitem aceder a tais processos.

Os grupos focais foram realizados em freguesias onde estava prevista a passagem da LMAT, nomeadamente em Barcelinhos, concelho de Barcelos (dois grupos focais); Tangil, concelho de Monção; Ribeira, concelho de Ponte de Lima; e Refóios, concelho de Ponte de Lima (um grupo focal por cada localidade). Os participantes foram recrutados através de organizações e associações locais (e.g., associações ambientalistas, grupos desportivos, escuteiros), recorrendo assim a "grupos naturais". Tal como proposto por Krueger e Casey (2015), as pessoas que participaram nos grupos focais partilhavam algumas características em comum, e foram recrutadas porque viviam ou trabalhavam nas localidades afetadas pelo projeto de construção da LMAT. Os grupos e organizações locais foram mapeados através de pesquisas na internet, sendo posteriormente convidados a participarem no estudo por email ou telefone. Solicitamos às organizações que recrutassem participantes para os grupos focais, procurando incluir diferentes perfis em termos de género, idade, e perfil de envolvimento com as organizações.

A amostra é novamente maioritariamente masculina (27 homens, 10 mulheres), mas mais jovem do que nas entrevistas (sete participantes tinham entre 18-25 anos; nove entre os 26 e os 35 anos; 16 entre os 36 e os 50 anos, quatro entre 51 e 65 anos; e finalmente um participante tinha mais do que 65 anos). Vinte e nove participantes viviam nas freguesias onde os grupos de discussão decorreram e oito trabalhavam ou tinham uma ligação significativa com o lugar ainda que não fossem residentes. Através dos grupos de discussão procurou-se compreender: a) se os participantes tinham tido conhecimento e se tinham participado no processo de consulta pública, e as visões dos participantes sobre o mesmo; b) impactos da linha de muita alta tensão; c) quem deveria conduzir o processo de consulta pública; d) quem deveria ser responsável pela disseminação de informação e que meios deveriam ser utilizados; e) qual a duração desejável do processo; f) que meios deveriam ser facultados para a participação cívica; g) como é que as opiniões deveriam ser tidas em conta; h) como deveria ser a tomada de decisão. Os grupos de discussão foram conduzidos por duas moderadoras, sendo que uma era responsável pela introdução dos tópicos relevantes para a discussão e a outra estava mais focada nas dinâmicas do grupo (e.g., linguagem corporal, participação desigual). 
Durante as sessões dos grupos focais, procurou-se incentivar a partilha de opiniões e experiências por parte de todos os participantes. Por exemplo, sempre que algum dos participantes estava menos participativo, uma das moderadoras dirigia-se diretamente ao participante solicitando que desse a sua opinião. Também procurou incentivar-se que os participantes partilhassem opiniões contraditórias ou dissidentes.

\section{ANÁLISE DOS DISCURSOS}

Nesta secção, apresentamos a análise das entrevistas e dos grupos de discussão. A estrutura tem como base uma análise temática guiada pelas noções de acesso, legitimidade e influência propostas por Senecah (2004). O programa Nvivo 12 foi utilizado como apoio e suporte para a organização dos dados. Inspiradas pelas abordagens da Análise Crítica de Discurso (Fairclough \& Wodak, 2006) e da Análise Positiva do Discurso (Hughes, 2018), analisamos os discursos dos cidadãos relativamente aos fatores que podem bloquear a participação, tal como as condições necessárias para o desenvolvimento de processos de consulta pública éticos e relevantes. A Análise Crítica de Discurso (ACD) combina "crítica ao discurso e explicação de como o discurso funciona e contribui para a realidade social existente, e é uma base para ação que vise a mudança da realidade social existente em determinados aspetos" (Fairclough, 2014). Noutras palavras, a ACD visa contribuir para a emancipação social através da análise de textos e do modo como esses textos se relacionam com práticas, processos e estruturas sociais. A maioria dos estudos na área da ACD focam-se apenas nos discursos que produzem discriminação, formas de abuso de poder e opressão. Propostas recentes sugerem uma Análise Positiva do Discurso (e.g., Hughes, 2018), o que implica uma análise mais focada nas práticas de linguagem que contrariam os problemas sociais existentes e que sugerem possibilidades e caminhos com vista a uma melhoria das condições sociais. Com base nestas duas abordagens à análise de discurso, neste artigo combinamos uma análise dos sentimentos (expressos) de exclusão e desempoderamento, com uma análise das estratégias propostas pelos cidadãos para reduzir ou eliminar os obstáculos à participação pública.

\section{NARRATIVAS DE EXCLUSÃO: FALTA DE ACESSO, INFORMAÇÃo E CONHECIMENTO}

Cerca de metade dos participantes mencionaram a falta de informação, quer em relação ao processo de consulta de pública, quer em relação aos impactos das linhas de muita alta tensão. De facto, a falta de informação foi recorrentemente referida como um dos principais motivos para a não participação na consulta pública. A grande maioria dos participantes atribuíram a responsabilidade pela não participação na consulta à falta de informação ou à ausência de informação adequada. Por exemplo, Manuel e José, residentes no concelho de Monção, referiram não terem tido acesso a nenhuma informação sobre a consulta:

Manuel - Ninguém ouviu falar disso aqui....

Entrevistadora - E o senhor, também não soube da consulta pública que houve? José - Nada, nada. Que consulta. Nada, nada. 
Armando - Não houve consulta nenhuma. Embora eles

digam que houve. (Entrevista de grupo, Monção)

Manuel tende a generalizar a sua falta de informação a toda a população da região. Da mesma forma, a própria existência do processo de consulta pública é questionada por José e refutada por Armando. O discurso de Armando revela várias dúvidas sobre a honestidade das entidades e dos técnicos envolvidos na consulta pública. Para além disso, a utilização de expressões vagas como "eles", típicas dos processos de categorização "nós/eles", implica implicitamente um "nós" (as pessoas da comunidade). Neste caso, a categoria "eles" representa as pessoas em cargos de poder, e o "nós" as pessoas que foram excluídas dos processos de participação. Este entrevistado deslegitima o processo de consulta, essencialmente porque não chegou aos cidadãos. Adicionalmente, a grande maioria dos participantes referiu que tinha a expectativa de que as instituições públicas partilhassem informação sobre o processo de consulta, bem como sobre os impactos das linhas de muita alta tensão, de forma a que conseguissem "construir uma opinião crítica e sustentada" (Elisa, grupo focal, Barcelinhos 1). Na mesma linha, a falta de suporte e de responsividade por parte das autoridades e instituições, são considerados na literatura como obstáculos significativos à participação pública (Lowndes, Pratchett \& Stoker, 2001).

$\mathrm{Tal}$ como nas entrevistas, os participantes nos grupos focais sugeriram diversas vezes que o processo de consulta pública tinha sido intencionalmente simulado, desde o início. De facto, o acesso à informação sobre o processo parece não ter sido assegurado de todo, ou então aconteceu tardiamente e/ou de forma inadequada, tal como Helena explicou: "pelo menos nós, foi só na parte final onde já quase mais nada havia a fazer porque já estava tudo decidido (...). Na freguesia só começaram a pedir assinaturas três dias antes [de fechar o processo]" (Helena, grupo focal, Ribeira). Estas e outras críticas estão direta e explicitamente relacionadas com o direito de acesso à consulta pública já que os participantes reclamam não ter tido informação suficiente sobre a consulta pública, em particular sobre a possibilidade de submeterem as suas sugestões (Senecah, 2004).

Ao não se verificarem as condições necessárias para o envolvimento inicial dos cidadãos no processo de consulta, os participantes tendem a percecionar todo o processo como enviesado e simulado (Rowe \& Frewer, 2000). A maioria dos participantes considera que a falta de informação e má gestão do processo foi deliberada e intencional, com o propósito de evitar contestação pública. Verifica-se assim um problema de falta de confiança relativamente aos processos de participação pública iniciados pelo Estado, o que provavelmente tende a influenciar a decisão de não participar em tais processos. Tal como referido por um dos participantes, as pessoas tiveram conhecimento sobre o projeto das linhas de muita alta tensão meramente por acaso: "e atenção, as pessoas tiveram conhecimento deste projeto porque lá calhou, houve uma falha em qualquer lado. Alguém que não estava dentro do sistema, mas que viu este processo e se revoltou" (Leonor, grupo focal, Refóios). Relativamente à consulta pública, um dos entrevistados de Gemieira apontou que "isto foi escondido de nós todos" (Fernando) e outra participante de Barcelinhos argumentou que: "se eles estivessem realmente interessados em ouvir a nossa opinião, teriam feito um processo mais claro" (Sofia, grupo focal, Barcelinhos 1). 
Para além disso, os poucos participantes que referiram ter tido acesso ao processo de consulta pública, afirmaram que a natureza técnica da linguagem utilizada nos documentos oficiais foi uma barreira à participação: "eu estive a ler um bocadinho, mas há partes que...É uma linguagem muito técnica. Não é propriamente para nós" (Rafaela, grupo focal, Tangil). É transversal aos participantes a vontade de ter mais informação sobre os impactos das linhas de muita alta tensão, sendo que a falta de disponibilização de informação sobre os riscos para a saúde foi considerada um aspeto particularmente alarmante:

Entrevistadora - Então acham que não foi bem conduzido?

Sérgio - Não. O que mais nos preocupa ninguém diz.

Lurdes - O que preocupa mais as pessoas é a questão de saú-

de e nessa parte dizem zero. (Grupo focal, Tangil)

De forma geral, os cidadãos sentem que a informação disponibilizada foi restrita e limitada de forma a, por um lado, evitar que o público tivesse conhecimento sobre o projeto de construção da linha de muita alta tensão; e por outro lado, de forma a limitar a possibilidade dos cidadãos terem voz, isto é, darem a sua opinião sobre o projeto proposto. Assim, os elementos mínimos que permitem o acesso à participação não foram facultados (Senecah, 2004), o que sugere que as instituições não estão interessadas nas visões, opiniões e preocupações dos cidadãos, ainda que digam o contrário (e.g., Arnstein, 1969; Rowe \& Frewer, 2000). A partir de um olhar ético, pode-se considerar que o público interessado não teve oportunidade genuína de aceder ao processo de consulta, nem foi disponibilizada informação suficiente que permitisse aos cidadãos compreender o procedimento de consulta pública ${ }^{9}$. As visões dos cidadãos sobre a falta de acesso, informação e conhecimento sugerem uma violação grave de vários princípios éticos, nomeadamente relacionados com abertura, acessibilidade e transparência do processo ${ }^{10}$, e também com a adequabilidade dos recursos e das ferramentas disponibilizadas para potenciar o envolvimento dos cidadãos.

\section{EXPERIÊNCIAS DA CONSULTA (SIMULADA): FORMATO, INTERAÇÕES E LEGITIMIDADE DOS CIDADÃOS}

O formato da consulta pública tem problemas óbvios no que se refere ao acesso, especialmente porque exclui à partida pessoas que não sabem ler ou escrever. Para além disso, não pressupõe nenhum debate ou deliberação e depende essencialmente de uma boa estratégia de informação (e respetiva cobertura mediática) conduzida pelo governo nacional e/ou local. Durante um processo de consulta pública, é esperado que o Estado português (normalmente através da Associação Portuguesa do Ambiente) organize sessões públicas que ajudem os cidadãos interessados a compreender os projetos a decorrer, bem como os potenciais impactos de tais projetos. Pelo que sabemos, durante o processo de consulta relativamente à LMAT prevista para o Norte de Portugal, apenas foi organizada uma sessão pública, em Monção, no dia 8 de fevereiro de 2014. Os poucos participantes neste estudo que estiveram presentes na referida sessão pública

\footnotetext{
9 Informação retirada de https://www.iap2.org/page/about

${ }^{10}$ Ver, por exemplo, https://www.iap2.org/page/about
} 
demonstraram uma enorme frustração relacionada com o modo como a sessão foi organizada, com a postura dos oradores, com o tipo de linguagem utilizada e com a própria gestão do tempo durante a sessão:

Rui - Eu não fiquei até ao final que aquilo nunca mais acabava, aquilo era, cada orador vinha com a sua teoria e aquilo prolongou-se e aquilo quando entrou nos debates propriamente dito, em que o povo se começou a manifestar, eu vim-me embora, que já eram quase oito horas e eu tive que me vir embora.

(...)

Rui - Começou às três horas. Aquilo eram sete horas e só tinha havido conversa da chacha.

Simão - Era, era conversa de chacha.

Rui - E havia uma senhora, uma senhora que pertencia à aquela empresa de luz e [Simão - A REN]. Isso nunca mais acabava.

Simão - Claro, isso é para chatear as pessoas

Rui - Porque depois é muita gente da aldeia.

Entrevistadora - Era linguagem técnica?

Rui - Claro, pois era mais técnica do que coisa. Ali estava muita gente da aldeia, mas eram mais pessoas que vivem a coisa no local, não é? E queriam-se manifestar e que nunca mais chegava a vez deles. Até porque a maior parte das pessoas foi-se embora. [Entrevistadora - Foram embora]. Pronto, viagens de $15 \mathrm{~km}$ e $18 \mathrm{~km}$ e estar ali toda a tarde e quase nem se perceber nada.

(...)

Simão - Não é. Eles vêm para falar para ninguém.

Entrevistadora - Porque era difícil de compreender o que estavam a dizer, não é?

Simão - Sim, pois claro. A falar para ninguém [Falam todos em simultâneo concordando com esta ideia]. Não vêm com dados concretos.

Rui - Ficou aí quase uma hora e meia a falar.

Simão - Para quê? Para afastar as pessoas. Para pôr as pessoas na rua.

Rui - A senhora falou, falou que nunca mais se (.) e termos técnicos e coisas.

Simão - É evidente, aquilo está feito para isso.

Rui - Veio um outro senhor depois dessa, rebater quase tudo aquilo que ela disse.

Simão - É evidente.

Entrevistadora - Que era também outro técnico?

Simão - E isso foi outra hora e meia. (Entrevista de grupo, Monção)

Esta descrição da dinâmica de interação entre os oradores e o público local revela que a possibilidade de o público influenciar estes processos é obstaculizada, à partida, por discursos institucionais que tendem a empoderar excessivamente os técnicos e especialistas, bloqueando assim a participação cívica, nomeadamente através da excessiva 
tecnologização das questões e respetiva despolitização (e.g., Carvalho et al., 2016). Apesar do projeto de construção da LMAT ter vários impactos potenciais na população local, podendo então ser considerada uma questão social e política que é localmente relevante, foi apresentado à população como uma questão meramente técnica. Este aspeto, aliado ao excessivo uso do tempo por parte dos técnicos durante as sessões públicas, "para pôr as pessoas na rua", limita fundamentalmente as oportunidades de participação. Os excertos apresentados acima demonstram as múltiplas formas em que os cidadãos analisam criticamente os objetivos estratégicos dos vários atores no poder, e revelam várias pistas sobre o modo como os cidadãos interpretam as intenções do Estado, das grandes empresas, e dos técnicos especialistas que os representam. Curiosamente, os entrevistados consideram que o propósito dos momentos de interação entre os técnicos e os cidadãos, é "afastar as pessoas" destas questões.

As dinâmicas de interação são descritas como desrespeitosas e desadequadas ao perfil da comunidade local e às suas circunstâncias. Tomando como referência Butler (1997), encontramos nesta entrevista de grupo referências à expectativa do público em ser abordado pelas autoridades, mas também um desejo de que a sua voz seja ouvida e reconhecida como legítima e várias referências ao modo como este desejo tem sido recorrentemente reprimido. Tal como Blüdhorn (2013) sugere, este tipo de discurso também poder ser considerado uma crítica à sessão pública por esta representar uma forma de "democracia simulada", em que determinadas práticas são utilizadas para criar a ilusão de liberdade política e igualdade e/ou em que "os governos são inspirados por, e respondem aos valores e necessidades expressos pela demo" (Blüdhorn, 2013, p. 28).

Assim, em vez de contribuir para a compreensão pública dos aspetos científicos, tecnológicos e ambientais associados ao projeto de construção da linha de muita alta tensão, a sessão pública narrada pelos participantes parece ter contribuído para intensificar a desconfiança e suspeição face ao Estado e às grandes empresas. Pela ótica de análise de discurso, o efeito pragmático deste tipo de sessões (em que os técnicos especialistas "falam para ninguém") é o desenvolvimento de formas de resistência face às autoridades, que passa pela crítica e ceticismo político. Na conversa reproduzida acima, os entrevistados reforçam as opiniões uns dos outros, como se pode verificar através do vocabulário utilizado ("claro"; "certo"; "é evidente"), desenvolvendo assim uma cultura partilhada de antagonismo em relação ao Estado e outros atores. O excerto da entrevista apresentada oferece várias pistas sobre a construção relacional das identidades, nomeadamente a partir da interação entre cidadãos e técnicos especialistas. Também parece reforçar o argumento de que a ética deve ser garantida por aqueles que lideram o processo de consulta (Fox \& Murphy, 2012). Assim, os técnicos devem respeitar os princípios éticos no desenho e implementação da consulta pública, evitando qualquer forma de manipulação e aquietação do público (Arnstein, 1969).

\section{RELAÇõES DE PODER E DESEJO DE INFLUÊNCIA}

A maioria dos participantes são bastante descrentes relativamente à possibilidade de influenciarem decisões políticas. Tendem a considerar o sistema político - por vezes referido como aliado do sistema económico - como indiferente à influência cidadã. 
Vários cidadãos evitam a participação pública, uma vez que a consideram inútil ou insignificante face ao poder do "sistema". Apesar de, nalgumas pessoas, esta descrença ser baseada em experiências individuais prévias de participação pública, a maioria dos participantes não referiu experiências de participação pública anteriores. Curiosamente, a descrença na capacidade de influência cívica foi várias vezes contraditada pelos casos recordados pelos participantes quando instigados a tal. De notar, no entanto, que, no decurso das entrevistas e grupos focais, alguns (poucos) participantes foram um pouco mais positivos relativamente ao impacto potencial da ação cívica. Por outro lado, outros não se conseguiam lembrar de nenhuma experiência de participação, com impacto ou sem impacto. Estas inconsistências encontradas nos discursos dos cidadãos, podem ser relacionadas com o paradoxo pós-democrático descrito por Blühdorn como a "simultaneidade de compromissos incompatíveis" (Blühdorn, 2013, p. 20), que pode ser observada nas democracias baseadas no consumo, em que a pressão social para mais democracia e equidade política (e.g., envolvimento de minorias e grupos não privilegiados), coexiste com uma democracia enfraquecida por uma sociedade "líquida", individualista e consumista.

As perspetivas que apresentamos acima, surgem também associadas a diversas desigualdades no acesso ao poder. Muitos participantes concordaram que alguns atores no campo político e económico - referidos como os "os grandes" ou como "as maiorias" - detêm (grande parte) do poder de tomada de decisão, enquanto que as "pessoas" são o elemento fraco. Os participantes consideram que a decisão de avançar (ou não) com a construção da linha de muita alta tensão é essencialmente dependente de uma relação de poder desigual em que os cidadãos são impotentes. A perceção de falta de influência através da consulta pública é explicitamente referida por Fernando: "basicamente, eu penso que já está tudo decidido" (Gemieira). Este tipo de discurso que sugere, de forma explícita, uma falta de poder de influência nas políticas ou nas instituições foi bastante consensual:

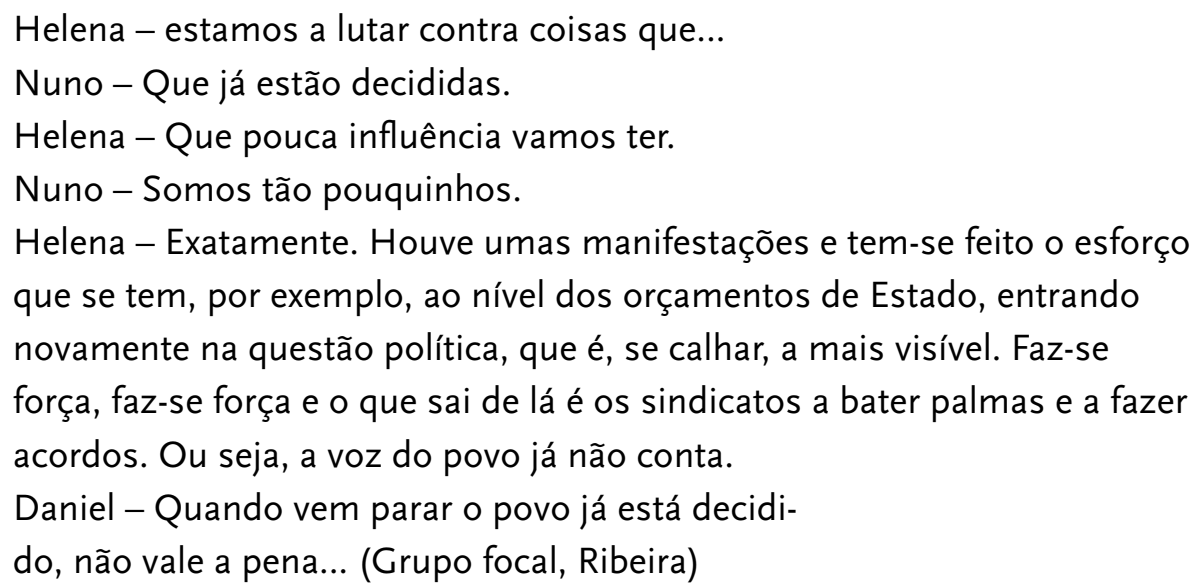

As posições apresentadas nos excertos acima sugerem uma rejeição do processo de consulta pública como um mecanismo legítimo de tomada de decisão, nomeadamente, porque as decisões estão meramente dependentes de questões relacionadas com a distribuição desigual de poder, e as ações e posições dos cidadãos são limitadas pelas ações e posições de outros que estão em posições de poder. Novamente, este discurso alude à natureza relacional na construção (discursiva) de identidades, que emerge de 
forma bastante clara nos dados. As possibilidades de participação oferecidas pelo Estado são vistas como negativas por vários participantes, que referem sentirem-se humilhados e ridicularizados. As expressões escolhidas pelos participantes para descrever as relações de poder indicam a importância destas questões para a legitimidade processual. Neste estudo, o Estado é apresentado como o "leão", e/no centro do poder, que considera os seus cidadãos como elementos com poucos conhecimentos e sem credibilidade:

Entrevistadora (dirigindo-se a Rui) - Mas isso [referindo-se à vontade

anteriormente expressa de melhorar o sistema nacional de pensões] levá-

-lo-ia no seu caso a participar nalgum protesto?

Simão - Se a coisa se justificasse, porque não?

Rui - Sim, pois claro, se a coisa se justificasse, se a gente visse que...

Simão - Que havia saída.

Rui - Que havia saída para essas coisas, tudo bem.

Simão - Agora assim não.

Rui - Agora ainda vai meter-se na boca do lobo.

Simão - Vai-se meter à cúpula do poder (...) do sistema, não pode...

Rui - Do sistema...

Entrevistadora - Se visse, se acreditasse que pudesse dar algum resulta-

do, não é isso que me está a dizer?

Rui - Exato. Assim não, assim é chover no molhado.

Simão - É. Para ser humilhado, para ser ridiculizado. Para di-

zerem que para o que dá uma pessoa com esta idade an-

dar metido nisto. (Entrevista de grupo, Monção)

Os dois oradores (de Monção) reforçam a posição um do outro repetindo o que disse o locutor anterior, completando as frases do outro, reforçando as afirmações do outro. Num grupo focal de Barcelinhos, um participante evocou uma fera para se referir ao poder que algumas pessoas têm: "porque depois chegam a determinado ponto e economicamente nem lhes é possível lutarem contra esses grandes tubarões" (André). As imagens de "leões" e "tubarões" são também utilizadas para descrever quem tem o poder de decidir. Do lado oposto, aqueles que participam e resistem são considerados "palhaços". O excerto abaixo pode, primeiramente, sugerir uma deslegitimação dos "manifestantes", por serem apenas "meia-dúzia" e "não dizerem nada". Um olhar mais aprofundado sobre a entrevista sugere que este discurso é provavelmente baseado numa forte descrença e desconfiança no poder que as pessoas têm para influenciar as políticas públicas:

Gil - Acho que as pessoas singulares (...) são muito pequenas para fazer, não vale a pena estar a lutar contra uma coisa que está assumida (...) Gil - Em princípio há, tem que haver (...) tem que haver aceitação dos municípios, tem que haver aceitação das freguesias, não é?

Entrevistadora - Lá está.

Gil - As freguesias é que têm que fazer o barulho.

Entrevistadora - As freguesias são toda a gente (h). 
Gil - As freguesias são, são toda a gente, são toda (...) somos, somos todos nós. Mas eles é que deveriam ter, estamos numa fase muito avançada do projeto, eles é que, estamos numa fase em que a linha está traçada, a linha tá definida, não é? Antes disso, deveria ter havido uma certa consulta às freguesias, aos municípios. Alguém disse alguma coisa sobre isso? Vêm agora os palhaços, a população, meia dúzia da população que nem dizem nada. Não! Isto devia ser passado para a freguesia, com muita antecedência, não é agora nesta fase.

De forma sucinta, nas falas dos cidadãos, as suas ações e posições são definidas como limitadas por e dependentes das ações e posições de outros. Consequentemente, o tipo de relações de poder referidas como características do processo de consulta pública parece ter um grande impacto no modo como os cidadãos se envolvem com as instituições públicas e com o próprio sistema democrático. Em última instância, estes discursos sugerem uma necessidade de repensarmos as abordagens à participação pública. Tal como referido anteriormente, os esforços para promover a participação devem ser acompanhados por apoio e suporte adequados, caso contrário, poderão vir a "fazer mais mal do que bem" (Fox \& Murphy, 2012, p. 212). Sucessivas experiências de participação pública caracterizadas por falta de acesso, legitimidade e influência, parecem levar a que os cidadãos se sintam desempoderados e desrespeitados, e poderão contribuir para que os cidadãos, ativa e intencionalmente, evitem qualquer envolvimento em processos de participação pública.

\section{IMAGINANDO ÉTICA NA PARTICIPAÇÃO PÚBLICA}

Seguindo a proposta de Senecah (2004), a nossa análise aponta para uma interdependência entre as questões de acesso, legitimidade e influência. Simultaneamente, as visões relativamente ao que é um processo de consulta pública ético e relevante estão bastante alinhadas com as experiências dos participantes. Neste sentido, os participantes sugerem uma variedade de estratégias para desenvolver processos de participação que assegurem o acesso, legitimidade e influência, tais como: criação de espaços de diálogo e reuniões informativas, assembleias públicas e reuniões com os promotores do projeto; contato direto com a população, por exemplo porta-a-porta; partilha de informação sobre o projeto e sobre a consulta por via postal, na fatura da eletricidade ou através de redes sociais; criação de um gabinete de informação na junta de freguesia ou na igreja local; disseminação da informação necessária através de panfletos e cartazes, em lojas e mercados locais; partilha de informação através dos média locais (jornais, rádio); e envolvimento de organizações locais para facilitar o processo de consulta pública. Todos os participantes concordam com a ideia de que, idealmente, os processos devem recorrer a uma combinação de meios e ferramentas de comunicação, de forma a garantir que os cidadãos - ou pelo menos a maioria dos cidadãos interessados - são incluídos no processo de consulta:

Rita - Eu acho que nós temos que nos atualizar um bocadinho. Os tempos são para as novas tecnologias e efetivamente divulgar através 
do Facebook e outras redes sociais hoje em dia é crucial. E não passar mensagens diferentes, passar uma só mensagem, mas adaptá-la aos diferentes tipos de públicos. As novas tecnologias são úteis para chegar a um público mais jovem, mas não nos podemos esquecer que aqui neste tipo de freguesias que são ainda tão rurais, há uma camada da população que não é formada, que não tem uma consciência tão trabalhada para estas questões e precisa de ser esclarecida por outros meios.

Alexandre - Têm que ser vários dispositivos.

Ana - Para mim já poderia ser um email, mas os mais velhos...

Sofia - Ou mesmo até mais eficaz, como a Câmara põe nas caixas do correio, um boletim informativo. (Grupo focal, Barcelinhos 1)

Tal como enfatizado por vários participantes, é também fundamental que a mensagem seja clara, coerente e acessível. Em termos de espaços de partilha de informação, a igreja local foi referida como o lugar ideal para chegar a todas as pessoas em zonas rurais. Vários participantes partilharam a ideia de que os anúncios públicos importantes poderiam ser feitos pela paróquia local: "era o padre anunciar na missa (...) é a primeira forma de chegar às pessoas" (Luísa, grupo focal, Refóios). A proposta de disseminação de informação sobre os impactos das linhas de muita alta tensão e o processo de consulta através do padre e das igrejas relembram-nos da necessidade de considerar o papel das variáveis contextuais nos processos de participação pública. Ao enquadrar as consultas públicas num contexto social e político, com características próprias e específicas, será mais fácil garantir que a consulta decorre de forma ética e relevante.

Em termos de mecanismos de participação, de notar que os participantes propuseram a criação de vários formatos, que passam pela consulta de opiniões através de questionários, por telefone ou online, petições e mesmo referendos populares. Estabelecendo várias ligações com o sistema de voto em Portugal, os participantes revelaram dificuldade em compreender os motivos para a não utilização de referendos num assunto tão "importante", como as linhas de muita alta tensão. Neste aspeto, verificou-se que as pessoas se referiram à falta de direitos de participação nestas questões de forma bastante emocional e solicitaram mais debates, manifestações, sessões públicas, mais espaços e momentos de tomada de decisão:

Luísa - Eu acho que em debates, a parte da divulgação da informação, de pessoas que sejam competentes, que tenham conhecimentos.

Helena - Manifestações.

Daniel - Nas reuniões.

Rogério - Uma reunião feita num domingo. Já que eles obrigam a ir votar nos

domingos também se podia marcar uma reunião num domingo.

Entrevistadora - E as pessoas iam lá e diziam o que é que pensavam?

Rogério - Sim.

Helena - Através de debates, manifestações, se houver caso disso, e através de votações.

Entrevistadora - Todas essas coisas?

Luísa - Tendo em conta que a votação sendo um voto secreto... 
Nuno - Talvez as pessoas vão votar e são capazes de não falar cara a cara.

Helena - E sendo o voto secreto é menos influenciável.(Grupo focal, Ribeira)

Apesar de se verificar uma falta de consenso relativamente à duração considerada ideal para o processo de consulta pública (e.g., três ou seis meses, um ou dois anos), os participantes parecem concordar que o processo de consulta deve ter a duração necessária para permitir alcançar toda a população interessada, ou pelo menos grande parte das pessoas. É considerado fundamental assegurar que todos os membros da comunidade têm oportunidade de participar no processo e de esclarecer todas as dúvidas que eventualmente possam ter: "o tempo necessário para as pessoas ficarem elucidadas" (Pedro, grupo focal, Tangil). De forma geral, é possível identificar nos discursos dos participantes os elementos mínimos indispensáveis para garantir o acesso à participação (e.g., oportunidades de aceder a informação e educação; e envolvimento no processo desde o início). Para além disso, os participantes também reclamam mais oportunidades e espaços de debate e diálogo, bem como fóruns deliberativos, o que está diretamente relacionado com as práticas necessárias para assegurar legitimidade processual (Senecah, 2004). As propostas mencionadas pelos participantes também reconhecem o papel de variáveis sociodemográficas e contextuais (tais como o nível de religiosidade da comunidade, relações sociais pré-existentes e níveis de educação) na limitação da participação pública (Baker \& Chapin, 2018).

É claro que os participantes querem ser ouvidos e, sobretudo, pretendem que as suas propostas e sugestões tenham um carácter vinculativo ou que pelo menos, sejam tidas em consideração: "como devia ser tomada a decisão? Era as pessoas terem algum poder vinculativo na decisão final, senão qual é o sentido de estar a discutir se no final" (Rodrigo, grupo focal, Barcelinhos 2). Para a maior parte dos participantes, as oportunidades oferecidas pelo formato de participação pública são frequentemente aparentes e ilusórias, no sentido em que apenas servem para criar falsas expectativas sobre o poder dos cidadãos nos processos de tomada de decisão. Não obstante, vários participantes associam legitimidade para exercer influência ao conhecimento técnico/especialista. Especificamente, expressões linguísticas como "viável", "informada", "prudente", "baseada no conhecimento", e "baseada em informação" são utilizadas para descrever o tipo de voz que deve influenciar as tomadas de decisão: "todas as opiniões deveriam ser pensadas, discutidas e ter uma conclusão realista e depois a decisão estaria aí, se realmente fosse realista" (Otávio, grupo focal, Tangil). Este e outros excertos sugerem posições ambivalentes relativamente às práticas de influência. Em última análise, os discursos são reveladores de como os cidadãos percecionam a sua própria legitimidade de decidir e influenciar questões socialmente relevantes.

\section{CONSIDERAÇÕES FINAIS}

Com base nas narrativas dos participantes sobre as questões de acesso, legitimidade e influência, a nossa análise sugere a consideração da ética da participação nos seus diferentes aspetos, de modo a assegurar processos de consulta pública realmente relevantes. Especificamente, estes aspetos relacionam-se com: o acesso à informação e 
ao conhecimento; o formato da consulta; as interações entre os técnicos e os cidadãos; a legitimidade do próprio processo; as relações e dinâmicas de poder; e, por fim, a capacidade de influência. De notar que as questões de acesso, legitimidade e influência são vistas como interdependentes (Senecah, 2004), e associadas a vários aspetos de uma ética da participação tais como a confiança, o respeito, a transparência, a abertura e a existência de relações igualitárias de poder.

Uma das conclusões principais que podemos retirar da nossa análise é que, nas consultas públicas, a lógica de um "tamanho e formato único" não é minimamente adequada. Os participantes apontaram várias soluções possíveis de modo a que os formatos, os espaços e o tempo da consulta pública estejam adaptados às características do contexto local e ao projeto em consulta. Isto remete-nos para a necessidade de considerar as dinâmicas contextuais quando pensamos em participação pública, e para a necessidade de desenvolver formatos que sejam contextual e localmente relevantes. Contrariamente a uma tendência para determinar critérios universais nos processos de participação pública (e.g., Rowe \& Frewer, 2000, 2004; Rowe et al., 2008), a nossa análise demonstra a importância de considerar as variáveis contextuais e também diversas dimensões específicas do projeto em consulta pública que poderão explicar o não envolvimento dos cidadãos (Baker \& Chapin, 2018; Webler \& Tuller, 2006). Isto implica necessariamente facultar meios e recursos adequados de participação, reconhecer as múltiplas formas de participação, reconhecer legitimidade a essas formas de participação, e considerar que diferentes públicos poderão ter diferentes preferências sobre como a participação pública deve ser conduzida. Seguindo a perspetiva da "ética do cuidado", implica necessariamente reconhecer particularidade e pluralidade no processo de consulta (Tronto, 2010).

É particularmente preocupante que as questões de acesso, legitimidade e influência nos processos de consulta pública sejam percebidas pelos cidadãos como desonestas, fraudulentas e desrespeitosas. Para resolver estes e outros problemas mencionados durante as entrevistas e grupos de discussão, os participantes sugerem a necessidade de mais abertura e transparência relativamente ao projeto de construção da LMAT, e também mais oportunidades de participação e influência. Tal como diversos autores têm vindo a sugerir, se o objetivo é melhorar os processos de participação pública, propósito e confiança são dois aspetos centrais a ter em conta (Baker \& Chapin, 2018; Senecah, 2004)". Na perspetiva de Arendt, se não existir uma oportunidade genuína de influenciar os resultados, nem o próprio processo, a participação pública não permite que a ação política ocorra, uma vez que a ação política é essencialmente "uma expressão da liberdade e individualidade humana, o princípio de algo novo que não é esperado de nada que aconteceu anteriormente" (Arendt, 1958, p. 178).

Todavia, a nossa análise sugere que a não participação nem sempre equivale a falta de interesse e alienação política (Cammaerts et al., 2014). Curiosamente, as pessoas revelaram um forte desejo de mais participação, e apresentaram várias propostas para o desenvolvimento de formas de participação éticas e relevantes. Tendo em conta que a consulta pública analisada neste estudo não foi considerada uma oportunidade genuína

\footnotetext{
"Informação também retirada de https://www.iap2.org/page/about
} 
de influenciar a tomada de decisão, os participantes propuseram diversas formas, meios e estratégias para melhorar as questões de acesso, legitimidade processual e influência. As sugestões indicam que os participantes têm grandes expectativas sobre a democracia deliberativa (Fishkin, 2009) e, em particular, verifica-se que, nestes discursos, as questões de influência emergiram como intrinsecamente ligadas a uma visão mais democrática do campo político. Em última instância, ao expressar o desejo de participar e ao reivindicarem processos de participação éticos e relevantes, os participantes no nosso estudo atribuem legitimidade à participação.

As propostas dos participantes para resgatar a participação pública de forma geral, e as consultas públicas em particular, contêm muitas expectativas em relação à democracia (Conrad et al., 2011) e sugerem desde logo a necessidade de politizar os processos de participação pública. É provável que a remoção do carácter político aos processos de decisão envolvidos nos formatos de participação pública leve à redução da agência coletiva percebida (Hay, 2007; Wood, 2015), o que por sua vez poderá ter implicações no modo como as pessoas veem e participam na política (van Wessel, 2010). Os obstáculos mencionados indicam que considerar dimensões de ética e relevância na participação pública, implica necessariamente reconhecer o direito democrático de incluir todos no processo de decisão e em condições em que todos se sintam motivados (Fishkin, 2009). Ao reivindicar o direito (desejado) de expressar as suas preocupações e de ser envolvido na consulta pública decorrida, os participantes reclamam agência política, e solicitam que as suas vozes sejam tratadas como legítimas perante o sistema político. A nossa análise sugere também que as questões de acesso, legitimidade, e influência podem contribuir para a revitalização da democracia, se forem baseadas na confiança, abertura, transparência e em noções de justiça. Pelo menos, poderão ajudar a contribuir para a diminuição de algumas das desigualdades de poder que parecem estar a criar constrangimentos à agência política dos cidadãos e à própria participação em processos de participação pública.

A análise apresentada neste artigo é baseada nas visões e nos discursos de um conjunto de cidadãos residentes em várias localidades do Norte de Portugal. Não obstante o rigor na abordagem qualitativa e da combinação de várias fontes de dados, o estudo é baseado nos discursos sobre um tipo particular de consulta pública, que ocorreu num contexto específico. Adicionalmente, importa salientar que a combinação de entrevistas com grupos focais também trouxe alguns desafios à análise. Apesar de termos procurado representar, quer os discursos dominantes, quer as opiniões dissidentes, é possível que os discursos dominantes estejam sobre-representados e que as dinâmicas de grupos tenham sido pouco analisadas (Smithson, 2000). Deve-se procurar continuar a explorar os significados associados à participação pública, dando centralidade às múltiplas vozes e perspetivas dos cidadãos nos processos políticos (van Wessel, 2010). Tal como o nosso estudo sugere, os discursos sobre a ética da participação pública merecem uma atenção especial.

Tradução: Maria Fernandes-Jesus, Eunice Castro Seixas e Anabela Carvalho 


\section{Agradecimentos}

Agradecemos a todos os participantes neste estudo pelo seu tempo e por partilharem as suas opiniões e experiências. Este estudo foi desenvolvido no âmbito do projeto COMPOLIS - Comunicação e Envolvimento Político com Questões Ambientais, financiado pela Fundação para a Ciência e a Tecnologia [EXPL/IVC-COM/1717/2012] através de fundos nacionais (PIDDAC) e cofinanciado pelo Fundo Europeu de Desenvolvimento Regional (FEDER) através do programa COMPETE - Programa Operacional Fatores de Competitividade.

\section{REFERÊNCIAS}

Amnå, E. \& Ekman, J. (2014). Standby citizens: diverse faces of political passivity. European Political Science Review, 6(2), 261-281.

Arendt, H. (1958). The human condition. Chicago: University of Chicago Press.

Arnstein, S. R. (1969). A ladder of citizen participation. Planning Practice and Research, 35(1), 216-224. https:// doi.org/10.1080/01944366908977225

Baker, S. \& Chapin, F. S. (2018). Going beyond "it depends:" the role of context in shaping participation in natural resource management. Ecology and Society, 23(1), 1-20. https://doi.org/10.5751/ES-09868-230120

Blühdorn, I. (2013). The governance of unsustainability: ecology and democracy after the post-democratic turn. Environmental Politics, 22(1), 16-36. https://doi.org/10.1080/09644016.2013.755005

Butler, J. (1997). The psychic life of power: theories in subjection. Stanford, CA: Stanford University Press.

Cammaerts, B., Bruter, M., Banaji, S., Harrison, S. \& Anstead, N. (2014). The myth of youth apathy: young Europeans' critical attitudes toward democratic life. American Behavioral Scientist, 58(5), 645-664. https://doi.org/10.1177/0002764213515992

Carpentier, N. (2012). The concept of participation: if they have access and interact, do they really participate? Revista Fronteiras - Estudos Midiáticos, 14(2), 164-177. https://doi.org/10.4013/fem.2012.142.10

Carvalho, A., Wessel, M. V. \& Maeseele, P. (2016). Communication practices and political engagement with climate change: a research agenda. Environmental Communication, 11(1), 122-135. https://doi.org/10.108 o/17524032.2016.1241815

Conrad, E., Cassar, L. F., Christie, M. \& Fazey, I. (2011). Hearing but not listening? A participatory assessment of public participation in planning. Environment and Planning C: Government and Policy, 29(5), 761782. https://doi.org/10.1068/c10137

Cornwall, A. (2002). Making spaces, changing places: situating participation in development. IDS Working Paper, 170. Brighton: Institute of Development Studies.

Dalton, R. J. (2008). Citizenship norms and the expansion of political participation. Political Studies, 56(1), 76-98.

Dalton, R. J. (2015). The good citizen: how a younger generation is reshaping American politics. Washington: CQ Press.

Dassonneville, R. \& Hooghe, M. (2018). Indifference and alienation: diverging dimensions of electoral dealignment in Europe. Acta Politica, 53(1), 1-23.

Davies, A. (2001). What silence knows - planning, public participation and environmental values. Environmental Values, 10(1), 77-102. https://doi.org/10.3197/096327101129340750

Decreto-Lei n. ${ }^{\circ}$ 69/2000, de 3 de maio, República Portuguesa. 
Decreto-Lei n. ${ }^{0}$ 197/2005, de 8 de novembro, República Portuguesa.

Ekman, J. \& Amnã, E. (2012). Political participation and civic: towards a new typology. Human Affairs, 22, 283300. https://doi.org/10.2478/s13374-012-0024-1

Etikan, I., Musa, S. A. \& Alkassim, R. S. (2016). Comparison of convenience sampling and purposive sampling. American Journal of Theoretical and Applied Statistics, 5(1), 1-4. https://doi.org/10.11648/j. ajtas.20160501.11

Fairclough, N. (2014). What is CDA? Language and power twenty-five years on. Retirado de https://lancaster. academia.edu/NormanFairclough

Fairclough, N. \& Wodak, R. (2006). Critical discourse analysis. In T. A. van Dijk (Ed.), Discourse as social interaction (pp. 258-284). Londres: Sage.

Fishkin, J. S. (2009). When the people speak: deliberative democracy and public consultations. Oxford: Oxford University Press.

Fox, C. \& Murphy, P. (2012). Environmental reviews and case studies: sometimes less is better: ethics of public participation. Environmental Practice, 14(3), 212-219. https://doi.org/10.1017/S1466046612000166

Häkli, J. \& Kallio, K. (2014). Subject, action and polis: theorizing political agency. Progress in Human Geography, 38(2) 181-200. https://doi.org/10.1177/0309132512473869

Hay, C. (2007). Why we hate politics. Cambridge: Polity Press.

Hendry, J. (2004). Decide, announce, defend: turning the NEPA process into an advocacy tool rather than a decision-making tool. In S. P. Depoe, J. W. Delicath, \& M.-A. Elsenbeer (Eds.), Communication and public participation in environmental decision-making (pp. 99-112). Albany: State University of New York Press.

Hughes, J. M. F. (2018). Progressing positive discourse analysis and/in Critical Discourse Studies: reconstructing resistance through progressive discourse analysis. Review of Communication, 18(3), 193211. https://doi.org/10.1080/15358593.2018.1479880

Kaehne, A. \& Taylor, H. (2016). Do public consultations work? The case of the Social Services and Well-being (Wales) Bill. Public Policy and Administration, 31(1), 80-99. https://doi.org/10.1177/0952076715595676

Krause, K. \& Schramm, K. (2011). Thinking through political subjectivity. African Diaspora, 4, 115-134. https:// doi.org/10.1163/187254611X607741

Krueger, R. A. \& Casey, M. A. (2015). Focus groups: a practical guide for applied research. Thousand Oaks: Sage.

Lowndes, V., Pratchett, L. \& Stoker, G. (2001). Trends in public participation: part 2 - citizens' perspectives. Public Administration, 79(2) 445-455.

Lusa (2015, 12 de fevereiro). Nova linha de alta tensão no Norte adiada. Público. Retirado de https://www. publico.pt/2015/02/12/local/noticia/projecto-de-linha-electrica-no-norte-adiado-1685895

Martin, T. (2007). Muting the voice of the local in the age of the global: how communication practices compromised public participation in India's Allain Dunhangan environmental impact assessment. Environmental Communication, 1, 171-193. https://doi.org/10.1080/17524030701642595

Norris, P. (2002). Democratic phoenix: reinventing political activism. Cambridge: Cambridge University Press.

Norris, P. (2011). Democratic deficit: critical citizens revisited. Cambridge: Cambridge University Press.

O'Faircheallaigh, C. (2010). Public participation and environmental impact assessment: purposes, implications, and lessons for public policy making. Environmental Impact Assessment Review, $30(1), 19-$ 27. https://doi.org/10.1016/j.eiar.2009.05.001 
Pepermans, Y. \& Maeseele, P. (2016). The politicization of climate change: problem or solution? Wiley Interdisciplinary Reviews: Climate Change, 7(4), 478-485. https://doi.org/10067/1334860151162165141

Putnam, R. D. (2000). Bowling alone: the collapse and revival of American community. Nova lorque: Simon \& Schuster.

Rowe, G. \& Frewer L. J. (2000). Public participation methods: a framework for evaluation. Science, Technology and Human Values, 25(1), 3-29. Retirado de https://www.jstor.org/stable/690198

Rowe, G. \& Frewer, L. J. (2004). Evaluating public-participation exercises: a research agenda. Science, Technology, Q Human Values, 29(4), 512-556. https://doi.org/10.1177/0162243903259197

Rowe, G., Horlick-jones, T., Walls, J., Poortinga, W. \& Pidgeon, N. F. (2008). Analysis of a normative framework for evaluating public engagement exercises: reliability, validity and limitations. Public Understanding of Science, 17(4), 419-441. https://doi.org/10.1177/0963662506075351

Scourfield, P. \& Burch, S. (2010). Ethical considerations when involving older people in public service participation processes. Ethics and Social Welfare, 4(3), 236-253.https://doi.org/10.1080/17496535.2010.516120

Senecah, S. L. (2004). The trinity of voice: the role of practical theory in planning and evaluating the effectiveness of environmental participatory processes. In S. P. Depoe, J. W. Delicath \& M. F. Elsenbeer (Eds.), Communication and public participation in environmental decision making (pp. 13-33). Albany: State University of New York Press.

Smithson, J. (2000). Using and analysing focus groups: limitations and possibilities. International Journal of Social Research Methodology, 3(2), 103-119.

Stewart, J. M. P. \& Sinclair, A. J. (2007). Meaningful public participation in environmental assessment: perspectives from Canadian participants, proponents, and government. Journal of Environmental Assessment Policy and Management, 9(2), 161-183. https://doi.org/10.1142/S1464333207002743

Tronto, J. C. (2010). Creating caring institutions: politics, plurality, and purpose. Ethics and Social Welfare, 4(2), 158-171. https://doi.org/10.1080/17496535.2010.484259

Van Damme, J. \& Brans, M (2012). Managing public consultation: a conceptual framework and empirical findings from Belgian case studies. Public Administration, 90(4), 1047-1066. https://doi. org/10.1111/j.1467-9299.2011.02014.x

Van Wessel, M. (2010). Political disaffection: what we can learn from asking the people. Parliamentary Affairs, 63(3), 504-523. https://doi.org/10.1093/pa/gsqo04

Verba, S. (2003). Would the dream of political equality turn out to be a nightmare? Perspectives on Politics, $1(4), 663-679$.

Verba, S., Schlozman, K. \& Brady, H. (1995). Voice and equality: civic voluntarism in American politics. Cambridge: Harvard University Press.

Webler, T. \& Tuler, S. (2006). Four perspectives on public participation process in environmental assessment and decision making: combined results from 10 case studies. The Policy Studies Journal, 34(4), 699-722.

Wood, M. (2015). Politicisation, depoliticisation and anti-politics: towards a multilevel research agenda. Political Studies Review, 14(4), 521-533. https://doi.org/10.1111/1478-9302.12074 


\section{NOTAS BIOGRÁFICAS}

Maria Fernandes-Jesus (PhD, Universidade do Porto) é Investigadora do Centro de Investigação e Intervenção Social, do Instituto Universitário de Lisboa (ISCTE-IUL), em Portugal. Desenvolve investigação sobre ação coletiva, ativismo ambiental, movimentos sociais, envolvimento comunitário e participação política entre grupos minoritários.

ORCID: https://orcid.org/oooo-0002-8868-1968

Email:maria.jesus@iscte-iul.pt

Endereço: Instituto Universitário de Lisboa (ISCTE-IUL, CIS, Lisboa), Avenida das Forças Armadas, 1649-026, Lisboa, Portugal

Eunice Castro Seixas é doutorada em Sociologia. Investigadora no Centro de Investigação em Sociologia Económica e das Organizações (SOCIUS) e no Centro de Ciências Sociais e Gestão do ISEG, da Universidade de Lisboa, em Portugal. Atualmente é Investigadora Principal do projeto de investigação "As crianças e o seu direito à cidade: Combater a desigualdade urbana através do desenho participativo de cidades amigas das crianças", financiado pela Fundação para a Ciência e a Tecnologia. Desenvolve investigação sobre participação das crianças no planeamento urbano, direitos urbanos, estudos críticos sobre transparência e discursos sobre inteligência e contra-terrorismo.

ORCID: https://orcid.org/oooo-0001-5356-6014

Email: euniceseixas@gmail.com

Morada: SOCIUS/CSG - Investigação em Ciências Sociais e Gestão, ISEG - Lisbon School of Economics \& Management, Rua Miguel Lupi, 20, 1249-078 Lisboa, Portugal

Anabela Carvalho (PhD, University College - Londres) é Professora Associada do Departamento de Ciências da Comunicação da Universidade do Minho, em Portugal. Desenvolve investigação sobre as diversas formas de ambiente, comunicação de ciência e política, com foco particular nas alterações climáticas. Publicou diversos livros, entre eles Communicating climate change: discourses, mediations and perceptions (2008), Citizen voices: enacting public participation in science and environment communication (com L. Phillips e J. Doyle; 2012), Climate change politics: communication and public engagement (com T. R. Peterson; 2012). Atualmente é Diretora do Doutoramento em Estudos de Comunicação: Tecnologia, Cultura e Sociedade.

ORCID: https://orcid.org/oooo-0002-7727-4187

Email: carvalho@ics.uminho.pt

Morada: Departamento de Ciências da Comunicação, Universidade do Minho, Campus de Gualtar, 4710-057 Braga, Portugal

* Submetido: 12/02/2019

* Aceite: 10/05/2019 